\title{
Intensified shigellosis epidemic associated with sexual transmission in men who have sex with men - Shigella flexneri and S. sonnei in England, 2004 to end of February 2015
}

I Simms ${ }^{1}$, N Field (nigel.field@phe.gov.uk) ${ }^{1,2}$, C Jenkins 3 , T Childs ${ }^{1}$, V L Gilbart ${ }^{1}$, T J Dallman³, P Mook ${ }^{4}$, P D Crook ${ }^{4}$, G Hughes $^{1}$

1. HIV and STI Department, Public Health England Health Protection Services, Colindale, United Kingdom

2. Department of Infection and Population Health, University College London, London, United Kingdom

3. Gastrointestinal Bacteria Reference Unit, Public Health England Reference Microbiology Services, Colindale, United Kingdom

4. Public Health England Health Protection Field Epidemiology Services, London, United Kingdom

Surveillance data suggest an intensification of the shigellosis epidemic associated with sexual transmission in men who have sex with men (MSM) in England with separate introductions into the population. In 2014, sexual transmission between MSM might have accounted for $97 \%, 89 \%$, and $43 \%$ of non-travel associated Shigella flexneri $3 a$ and S. flexneri $2 a$, and $S$. sonnei diagnoses. Clinicians should sensitively ascertain sexual history for men with enteric infections to facilitate prompt diagnosis and appropriate management.

\section{Intensification of shigellosis transmission between men who have sex with men Laboratory diagnoses of Shigella flexneri $2 \mathrm{a}$ in adult men without a reported travel history have increased markedly from 73 cases in 2013 to 220 cases in 2014 in England, while diagnoses in women have remained low (13 cases for each year). S. sonnei diagnoses in men have increased from 189 cases to 267 cases over the same period, again without increases in women. This pattern mirrors an earlier epidemic, from 2009, of S. flexneri za associated with sexual transmission between men. Here we report preliminary data sug- gesting an intensification of the shigellosis epidemic associated with sex between men in England continu- ing into 2015.}

\section{Background}

There are four species of Gram-negative bacteria of the genus Shigella that cause severe bacillary dysentery in humans (S. flexneri, S. sonnei, S. boydii, and S. dysenteriae) with over 50 serotypes described. Although many cases in England are associated with travel to high-incidence regions such as the Indian subcontinent, North and East Africa and South America, outbreaks of S. flexneri and S. sonnei associated with sexual transmission between men who have sex with men (MSM) have been reported in the United Kingdom (UK), Germany, Spain, Australia, Canada and the United States [1-9].

\section{Shigella reporting in England}

Faecal specimens from cases with symptoms of gastrointestinal infection are submitted to local hospital, private and regional laboratories in England for culture of Shiga toxin-producing Escherichia coli, Salmonella, Campylobacter and Shigella species. Local hospital laboratories are recommended to submit presumptive strains of Shigella flexneri and other Shigella spp. to the Public Health England (PHE) national reference laboratory in London, the Gastrointestinal Bacteria Reference Unit (GBRU), for confirmation and typing, using standard biochemistry and serological tests [10]. Neither sexual behaviour nor orientation are routinely collected in this dataset, but the number of cases associated with sexual transmission among men may be approximated by using the GBRU typing data to identify diagnoses for men and women aged 16 to 60 years and excluding cases where recent travel outside the UK was reported. Given an assumption that equal numbers of men and women would be affected if transmission between men were not a risk factor, excess male cases are deemed likely to be in MSM.

We have previously reported a national outbreak and investigation of $S$. flexneri za occurring in MSM between 2009 and 2011 [11]. Most of these were white, UK-born MSM, many were HIV-positive, and they reported being part of dense sexual networks involving high numbers of casual and regular partners. This outbreak was associated with (i) low awareness about the risk of enteric infections, (ii) chemsex (sexual activity while under the influence of [typically] stimulant drugs), and (iii) meeting sex partners and locating sex parties through social and sexual networking applications $[12,13]$. 
Patients aged 16 to 60 years diagnosed with Shigella spp. infection with no reported history of travel outside the United Kingdom, by sex, and male to female sex ratios, England, 2004-2014 ( $\mathrm{n}=4,909)$

\begin{tabular}{|c|c|c|c|c|c|c|c|c|c|c|c|c|c|c|}
\hline Shigella species & Serotype & $\begin{array}{l}\text { Sex } \\
\text { and sex } \\
\text { ratio }\end{array}$ & 2004 & 2005 & 2006 & 2007 & 2008 & 2009 & 2010 & 2011 & 2012 & 2013 & 2014 & Total \\
\hline \multirow{15}{*}{ S. flexneri } & \multirow{3}{*}{$1 b$} & Male & 8 & 6 & 16 & 18 & 12 & 9 & 8 & 9 & 17 & 7 & 9 & 119 \\
\hline & & Female & 5 & 2 & 6 & 5 & 7 & 8 & 4 & 5 & 7 & 10 & 4 & 63 \\
\hline & & Ratio & 1.6 & 3.0 & 2.7 & 3.6 & 1.7 & 1.1 & 2.0 & 1.8 & 2.4 & 0.7 & 2.3 & 1.9 \\
\hline & \multirow{3}{*}{$2 a$} & Male & 9 & 21 & 27 & 18 & 22 & 23 & 50 & 30 & 42 & 73 & 220 & 535 \\
\hline & & Female & 8 & 16 & 28 & 21 & 18 & 17 & 14 & 21 & 12 & 13 & 13 & 181 \\
\hline & & Ratio & 1.1 & 1.3 & 1.0 & 0.9 & 1.2 & 1.4 & 3.6 & 1.4 & 3.5 & 5.6 & 16.9 & 3.0 \\
\hline & \multirow{3}{*}{$3 a$} & Male & 3 & 6 & 11 & 11 & 18 & 65 & 77 & 83 & 85 & 154 & 118 & 631 \\
\hline & & Female & 5 & 5 & 5 & 6 & 8 & 8 & 9 & 10 & 10 & 15 & 2 & 83 \\
\hline & & Ratio & 0.6 & 1.2 & 2.2 & 1.8 & 2.3 & 8.1 & 8.6 & 8.3 & 8.5 & 10.3 & 59.0 & 7.6 \\
\hline & \multirow{3}{*}{6} & Male & 4 & 5 & 10 & 12 & 4 & 6 & 6 & 9 & 11 & 8 & 4 & 79 \\
\hline & & Female & 1 & 10 & 14 & 9 & 13 & 14 & 15 & 12 & 11 & 7 & 2 & 108 \\
\hline & & Ratio & 4.0 & 0.5 & 0.7 & 1.3 & 0.3 & 0.4 & 0.4 & 0.8 & 1.0 & 1.1 & 2.0 & 0.7 \\
\hline & \multirow{3}{*}{ Other } & Male & 11 & 6 & 9 & 21 & 15 & 14 & 33 & 31 & 45 & 37 & 36 & 258 \\
\hline & & Female & 7 & 4 & 13 & 9 & 6 & 15 & 15 & 13 & 11 & 14 & 12 & 119 \\
\hline & & Ratio & 1.6 & 1.5 & 0.7 & 2.3 & 2.5 & 0.9 & 2.2 & 2.4 & 4.1 & 2.6 & 3.0 & 2.2 \\
\hline \multirow{3}{*}{ S. sonnei } & \multirow{3}{*}{ NA } & Male & 76 & 73 & 52 & 85 & 83 & 87 & 147 & 135 & 144 & 189 & 267 & 1,338 \\
\hline & & Female & 48 & 71 & 89 & 119 & 94 & 125 & 133 & 84 & 63 & 95 & 106 & 1,027 \\
\hline & & Ratio & 1.6 & 1.0 & 0.6 & 0.7 & 0.9 & 0.7 & 1.1 & 1.6 & 2.3 & 2.0 & 2.5 & 1.3 \\
\hline \multirow{3}{*}{ S. boydii } & \multirow{3}{*}{ NA } & Male & 9 & 7 & 17 & 14 & 12 & 5 & 10 & 5 & 5 & 13 & 9 & 106 \\
\hline & & Female & 4 & 11 & 13 & 16 & 17 & 9 & 20 & 11 & 9 & 12 & 9 & 131 \\
\hline & & Ratio & 2.3 & 0.6 & 1.3 & 0.9 & 0.7 & 0.6 & 0.5 & 0.5 & 0.6 & 1.1 & 1.0 & 0.8 \\
\hline \multirow{3}{*}{ S. dysenteriae } & \multirow{3}{*}{ NA } & Male & 2 & 2 & 2 & 3 & 12 & 2 & 7 & 2 & 4 & 1 & 2 & 39 \\
\hline & & Female & 2 & 6 & 4 & 10 & 4 & 4 & 9 & 7 & 9 & 2 & 5 & 62 \\
\hline & & Ratio & 1.0 & 0.3 & 0.5 & 0.3 & 3.0 & 0.5 & 0.8 & 0.3 & 0.4 & 0.5 & 0.4 & 0.6 \\
\hline \multirow{3}{*}{ Species unidentified } & \multirow{3}{*}{ NA } & Male & 1 & 3 & 3 & 5 & 2 & 0 & 0 & 0 & 0 & 1 & 0 & 15 \\
\hline & & Female & 2 & 3 & 5 & 3 & 1 & 0 & 1 & 0 & 0 & 0 & 0 & 15 \\
\hline & & Ratio & 0.5 & 1.0 & 0.6 & 1.7 & 2.0 & NA & 0.0 & NA & NA & NA & NA & 1.0 \\
\hline Total & NA & NA & 205 & 257 & 324 & 385 & 348 & 411 & 558 & 467 & 485 & 651 & 818 & 4,909 \\
\hline
\end{tabular}

NA: not applicable.

The male to female sex ratios $\geq 2.0$ are highlighted in bold.

\section{Recent trends in shigellosis in England}

We examined recent trends in national Shigella spp. diagnoses to explore whether there is evidence for (i) ongoing sexual transmission of S. flexneri $3 a$ and (ii) transmission of other Shigella serotypes or species among men.

Between 1 January 2004 and 28 February 2015, the total number of Shigella spp. diagnoses in England among 16 to 60 year olds was 9,534 and of these, 5,051 ( $53 \%$ ) were not known to be associated with travel outside the UK. Among those without recent travel history, diagnoses of S. flexneri 3a, S. flexneri $2 \mathrm{a}$, and S. sonnei accounted for $77 \%(3,795 / 4,909)$ of all cases (Table). During the study period, 262 unique laboratories submitted isolates of S. flexneri and 254 laboratories submitted isolates of $S$. sonnei.

Diagnoses of $S$. flexneri $3 a$ in men increased steadily from 2004 to 2013 (from 3 to 154 cases) and fell in 2014 (118 cases), with sharp increases noted in 2009 and 2013; diagnoses in women during this period remained low (Table; Figure 1A). Diagnoses of
S. flexneri $2 \mathrm{a}$ in men followed a similar pattern, although increases emerged later, rising from a baseline of nine cases in 2004 with peaks in 2010 (50 cases) and 2014 (220 cases); diagnoses in women during this period remained low (Table; Figure $1 \mathrm{~A}$ ). Diagnoses of $S$. sonnei in men began to exceed those in women ( 147 compared with 133 cases) in 2010, and have since risen steadily in men (267 cases in 2014) while remaining stable in women (Table; Figure 1B).

Male to female sex ratios also rose substantially during this period, and peaked in 2014 at 59.0:1, 16.9:1 and 2.5:1 for S. flexneri 3a, S. flexneri $2 a$, and S. sonnei (Table). The age distribution for cases of $S$. flexneri $3 a, S$. flexneri $2 a$, and $S$. sonnei was similar for men and women: $65 \%(1,629 / 2,504)$ of male cases and $61 \%$ $(783 / 1,291)$ of female cases were in those aged 25 to 44 years. However, geographic distribution differed: $64 \%(1,574 / 2,504)$ of male cases of $S$. flexneri $2 a, S$. flexneri $3 a$ and $S$. sonnei were reported by laboratories in London, Manchester, or Brighton, whereas only $38 \%$ $(491 / 1,291)$ of female cases were from these areas. 
In 2014, among those with no recent travel history and assuming all excess male cases were in MSM, we approximate that 116 cases of S. flexneri 3 a ( $97 \%$ of all excess cases), 207 of S. flexneri $2 a$ (89\%), and 161 of S. sonnei (43\%) might have been acquired through sex between MSM.

High levels of transmission of S. flexneri za, S. flexneri $2 \mathrm{a}$, and $S$. sonnei in men have been sustained into 2015 (Figure 2). Monthly reporting data suggest that a switch in the predominant serotype of S. flexneri from type $3 a$ to type 2 a occurred from March 2014.

\section{Discussion and conclusion}

Laboratory data over an 11-year period show ongoing endemic transmission of $S$. flexneri $3 a$ among men since 2009, and emerging epidemics of S. flexneri $2 \mathrm{a}$ and $S$. sonnei among men since 2011. Diagnoses in women during the same period have remained stable or declined. These data strongly suggest an intensification of the previously reported shigellosis epidemic in England associated with sexual transmission between MSM. The actual numbers are probably underestimated due to individuals in the community not seeking healthcare or not providing diagnostic stool specimens.

Early investigations into the $S$. flexneri za outbreak in 2011 failed to identify a point source and found most cases occurred in MSM [11-13]. The present analysis lacks sexual behaviour data, but the concentration of shigellosis diagnoses in urban settings, where we know rates of HIV, gonorrhoea and syphilis in MSM are high, and the increase in specific strains and serotypes found in adult men and not women is consistent with most likely continued sexual transmission of Shigella spp. among MSM. Nevertheless, there are other possible explanations for the excess in men. While reporting guidelines have not changed during the study period, some reporting practices may have changed leading to more samples obtained from men than from women being referred by laboratories. However, it seems unlikely that this would fully explain the extent of increases seen. Proactive campaigns have been undertaken by Public Health England (PHE) and the Terrence Higgins Trust (www.tht.org.uk/shigella) to alert general practitioners (GPs) and other health professionals to sexually transmissible enteric infections (STEI) in MSM and to raise awareness among MSM through social media, the gay press, and leaflets in health clinics. These campaigns may have increased healthcare seeking and diagnostic testing among men. However, the campaigns did not start until 2013, after increases in Shigella spp. diagnoses were first observed.

The emergence of these STEls has coincided with increased diagnoses of gonorrhoea, lymphogranuloma venereum, infectious syphilis and a recent cluster of verocytotoxin-producing Escherichia coli 0117: $\mathrm{H}_{7}$ among MSM, particularly those co-infected with HIV [14-17]. The characteristics of men affected by these overlapping epidemics are very similar and

\section{FIGURE 1}

Patients aged 16 to 60 years diagnosed with

(A) Shigella flexneri serotypes $2 \mathrm{a}$ and $3 \mathrm{a}(\mathrm{n}=1,430)$ and

(B) S. sonnei $(\mathrm{n}=2,365)$, with no reported history of travel outside the United Kingdom, by sex, England, 2004-2014
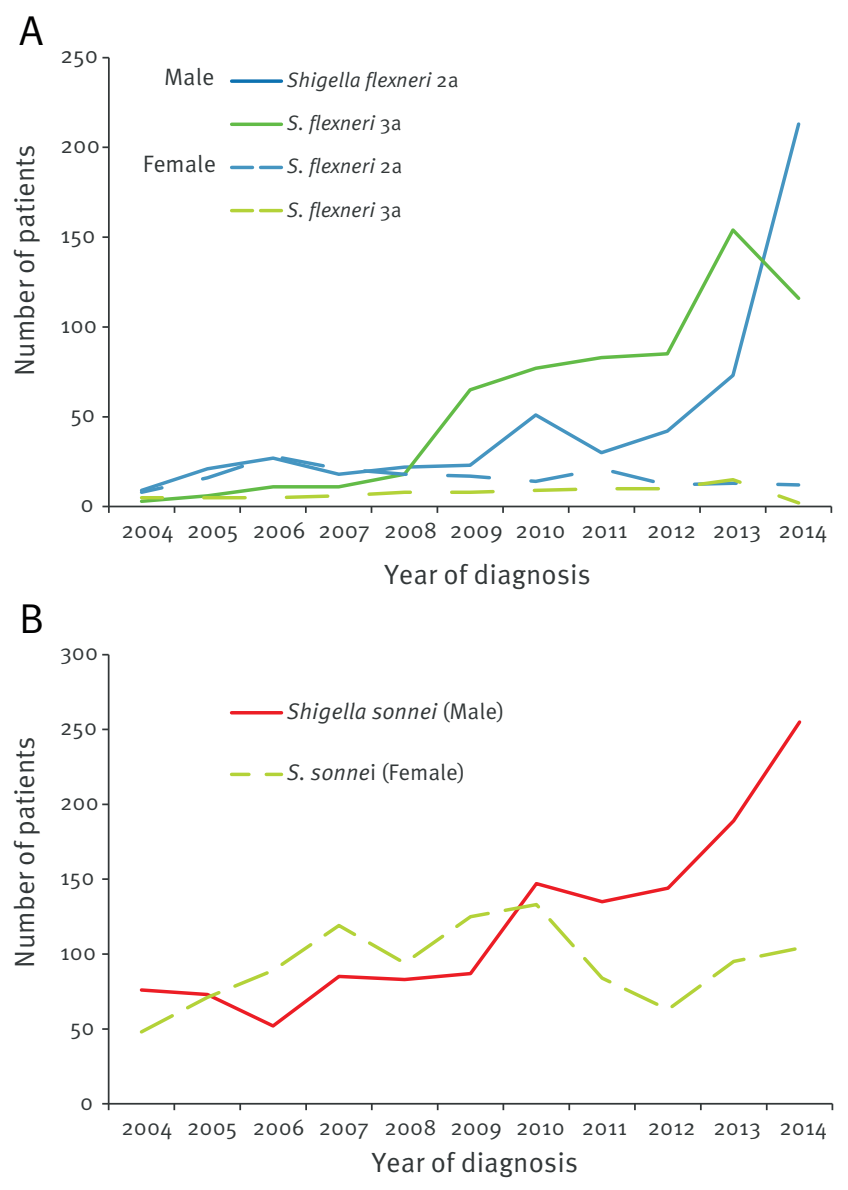

this suggests an intensification of sexual networking among HIV-diagnosed MSM engaging in HIV seroadaptive behaviours, possibly facilitated by geo-spatial apps [14-18]. Indeed, the different timing and heterogeneity in species and types indicate separate introductions of Shigella spp. into this population, and is consistent with this hypothesis.

Rapid intercontinental dissemination through sexual transmission in MSM of a S. flexneri za lineage with an azithromycin-resistance conferring plasmid has recently been demonstrated [19], and outbreaks of other STIs in MSM can spread quickly across Europe [20]. There is evidence that MSM may be more likely to engage in sexual risk behaviours while travelling abroad [21], raising the possibility of shigellosis outbreaks occurring elsewhere in Europe. We are currently reviewing laboratory reports of other enteric pathogens to explore whether sex between men might be an important route of transmission. MSM with symptoms of enteric pathogens may present to a range of healthcare settings including primary care, emergency departments, and specialist sexual health and gastroenterology services. To limit missed diagnostic opportunities, facilitate prompt diagnosis and appropriate 
Men aged 16 to 60 years diagnosed with Shigella flexneri 2a, S. flexneri 3a, and S. sonnei with no reported history of travel outside the United Kingdom, by month, England, January 2013-February 2015 ( $\mathrm{n}=1,271)$

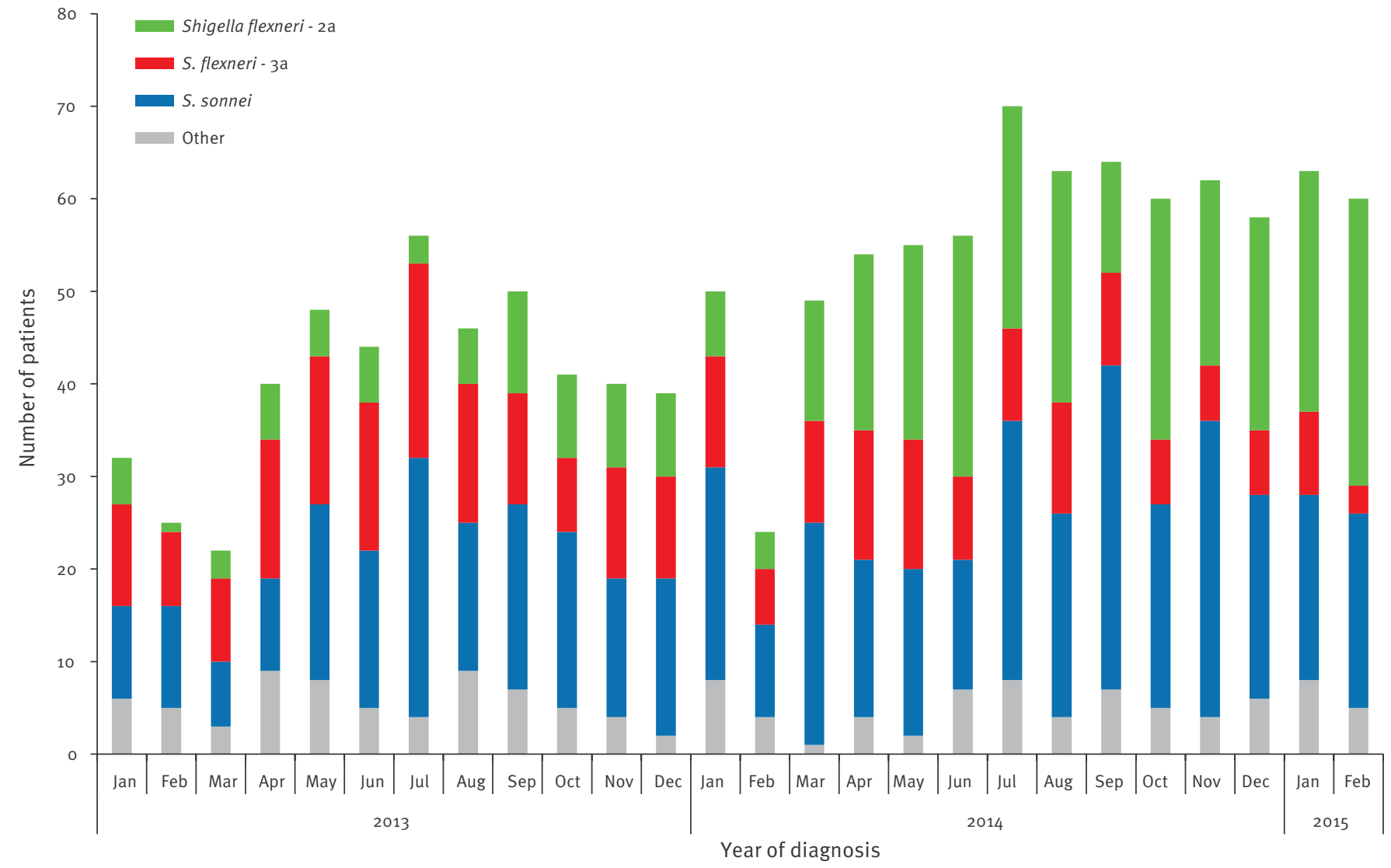

management, including partner notification and appropriate antibiotic stewardship, healthcare professionals need to recognise the potential for STEls in MSM and sensitively ascertain sexual history. Public health actions for shigellosis cases are described [22], but for MSM they should additionally include advice about when to resume sexual activity, partner notification, preventative advice about risky sexual behaviours, and screening for co-infection with STIs.

\section{Acknowledgements}

We would like to thank all reporting laboratories, Mark McCall and Malcolm Canvin (HIV and STI Department, PHE Health Protection Services).

\section{Conflict of interest}

None declared.

\section{Authors' contributions}

IS, NF, and GH drafted the manuscript. TC undertook data analysis assisted by CJ and TJD. VLG, PM and PDC contributed to data interpretation and revised the manuscript.
References

1. Drusin LM, Genvert G, Topf-Olstein B, Levy-Zombek E. Shigellosis. Another sexually transmitted disease? $\mathrm{Br}$ J Vener Dis. 1976;52(5):348-50. PMID:1036464

2. Centers for Disease Control and Prevention (CDC). Shigella sonnei outbreak among men who have sex with men--San Francisco, California, 2000-2001. MMWR Morb Mortal Wkly Rep. 2001;50(42):922-6. PMID:11699845

3. O'Sullivan B, Delpech V, Pontivivo G, Karagiannis T, Marriott D, Harkness J, et al. Shigellosis linked to sex venues, Australia. Emerg Infect Dis. 2002;8(8):862-4. http://dx.doi.org/10.3201/ eido808.010534 PMID:12141976

4. Institut RK. Shigellose: Gehäuftes Auftreten bei Männern in Berlin im Jahr 2004. [Shigellosis: High incidence among men in Berlin in 2004]. Epidemiologisches Bulletin. 2005;8:5963. German. Available from: http://www.rki.de/DE/Content/ Infekt/EpidBull/Archiv/2005/Ausgabenlinks/08_05. pdf?__blob=publicationFile

5. Marcus U, Zucs P, Bremer V, Hamouda O, Prager R, Tschaepe $\mathrm{H}$, et al. Shigellosis - a re-emerging sexually transmitted infection: outbreak in men having sex with men in Berlin. Int J STD AIDS. 2004;15(8):533-7. http://dx.doi. org/10.1258/0956462041558221 PMID:15307964

6. Culqui DR, García-de-Olalla-Rizo P, Alva-Chavez KP, Lafuente S, Rius C, de Simón M, et al. Análisis del patrón epidemiológico de la shigelosis en Barcelona entre 1988 y 2012: ies una infección de transmisión sexual emergente? [Analysis of the epidemiological pattern of Shigellosis in Barcelona between 1988 and 2012: Is it an emerging sexually transmitted infection?]. Enferm Infecc Microbiol Clin. 2014. Spanish.

7. Wilmer A, Romney MG, Gustafson R, Sandhu J, Chu T, Ng C, et al. Shigella flexneri serotype 1 infections in men who have sex with men in Vancouver, Canada. HIV Med. 2015;16(3):168-75. http://dx.doi.org/10.1111/hiv.12191 PMID:25656740

8. Gaudreau C, Bruneau A, Ismaïl J. Outbreak of Shigella flexneri and Shigella sonnei enterocolitis in men who have 
sex with men, Quebec, 1999 to 2001. Can Commun Dis Rep. 2005;31(8):85-90. PMID:15875326

9. Morgan O, Crook P, Cheasty T, Jiggle B, Giraudon I, Hughes $\mathrm{H}$, et al. Shigella sonnei outbreak among homosexual men, London. Emerg Infect Dis. 2006;12(9):1458-6o. http://dx.doi. org/10.3201/eid1209.060282 PMID:17073105

10. Bergey's Manual of Systematic Bacteriology. The

Proteobacteria (2nd Edition) Eds: Garrity GM, Brenner DJ, Krieg NR and Staley JT. 2005; Springer, New York.

11. Borg ML, Modi A, Tostmann A, Gobin M, Cartwright J, Quigley $C$, et al. Ongoing outbreak of Shigella flexneri serotype za in men who have sex with men in England and Wales, data from 2009-2011. Euro Surveill. 2012;17(13):20137. PMID:22490381

12. Gilbart VL, Simms I, Gobin M, Oliver I, Hughes G. Highrisk drug practices in men who have sex with men. Lancet. 2013;381(9875):1358-9. http://dx.doi.org/10.1016/S01406736(13)60882-X PMID:23601946

13. Gilbart VL. Simms I, Jenkins C, Furegato M, Gobin M, Oliver I, et al. Sex, drugs and smart 'phone applications: findings from semi-structured interviews with men who have sex with men diagnosed with Shigella flexneri $3 a$ in England and Wales. Sex Transm Infect. 2015. Forthcoming.

14. Hughes G, Field N. The epidemiology of sexually transmitted infections in the UK: impact of behavior, services and interventions. Future Microbiol. 2015;10(1):35-51. http://dx.doi. org/10.2217/fmb.14.110 PMID:25598336

15. Hughes G, Alexander S, Simms I, Conti S, Ward H, Powers C, et al.; LGV Incident Group. Lymphogranuloma venereum diagnoses among men who have sex with men in the U.K.: interpreting a cross-sectional study using an epidemic phase-specific framework. Sex Transm Infect. 2013;89(7):5427. http://dx.doi.org/10.1136/sextrans-2013-051051 PMID:23851189

16. Jebbari H, Simms I, Conti S, Marongiu A, Hughes G, Ward H, et al. Variations in the epidemiology of primary, secondary and early latent syphilis, England and Wales: 1999 to 2008. Sex Transm Infect. 2011;87(3):191-8.http://dx.doi.org/10.1136/ sti.2009.040139 PMID:21262786

17. Simms I, Gilbart VL, Byrne L, Jenkins C, Adak GK, Hughes G, et al. Identification of verocytotoxin-producing Escherichia coli 0117: $\mathrm{H}_{7}$ in men who have sex with men, England, November 2013 to August 2014. Euro Surveill. 2014;19(43):20946. http://dx.doi.org/10.2807/1560-7917.ES2014.19.43.20946 PMID:25375900

18. Malek R, Mitchell H, Furegato M, Simms I, Mohammed H, Nardone A, et al. Contribution of transmission in HIV-positive men who have sex with men to evolving epidemics of sexually transmitted infections in England: an analysis using multiple data sources, 2009-2013. Euro Surveill. 2015;20(15).

19. Baker K, Dallman T, Ashton PM, Day M, Hughes G, Crook PD, et al. Intercontinental dissemination of azithromycin resistant shigellosis through sexual transmission: a cross sectional study. Lancet Infect Dis. 2015. Forthcoming.

20. van de Laar MJ. The emergence of LGV in western Europe: what do we know, what can we do? Euro Surveill. 2006;11(9):146-8. PMID:17075163

21. Vanden Berghe W, Nöstlinger $C$, Hospers H, Laga M. International mobility, sexual behaviour and HIV-related characteristics of men who have sex with men residing in Belgium. BMC Public Health. 2013;13(1):968. http://dx.doi. org/10.1186/1471-2458-13-968 PMID:24139406

22. PHLS Advisory Committee on Gastrointestinal Infections.

Preventing person-to-person spread following gastrointestinal infections: guidelines for public health physicians and environmental health officers. Commun Dis Public Health. 2004;7(4):362-84. PMID:15786582 